\title{
LONGITUDINAL STRUCTURE IN ATOMIC OXYGEN CONCENTRATIONS OBSERVED WITH WINDII ON UARS
}

\author{
G.G. Shepherd ${ }^{1}$, G. Thuillier ${ }^{2}$, B.H. Solheim ${ }^{1}$, S. Chandra ${ }^{3}$, L.L. Cogger ${ }^{4}$, M.L. Duboin ${ }^{5}$ \\ W.F.J. Evans ${ }^{6}$, R.L. Gattinger ${ }^{7}$, W.A. Gault ${ }^{1}$, M. Herse ${ }^{2}$, A Hauchecorne ${ }^{2}$, C. Lathuilliere, \\ E.J. Llewellyn ${ }^{9}$, R.P. Lowe ${ }^{10}$, H. Teitelbaum ${ }^{11}$, and F. Vial ${ }^{11}$.
}

\begin{abstract}
WINDII, the Wind Imaging Interferometer on the Upper Atmosphere Research Satellite, began atmospheric observations on September 28, 1991 and since then has been collecting data on winds, temperatures and emissions rates from atomic, molecular and ionized oxygen species, as well as hydroxyl. The validation of winds and temperatures is not yet complete, and scientific interpretation has barely begun, but the dominant characteristic of these data so far is the remarkable structure in the emission rate from the excited species produced by the recombination of atomic oxygen. The latitudinal and temporal variability has been noted before by many others. In this preliminary report on WINDII results we draw attention to the dramatic longitudinal variations of planetary wave character in atomic oxygen concentration, as reflected in the OI $557.7 \mathrm{~nm}$ emission, and to similar variations seen in the Meinel hydroxyl band emission.
\end{abstract}

\section{Introduction}

Ever since Lord Rayleigh's (1930) first absolute emission rate determination of the night airglow OI $557.7 \mathrm{~nm}$ emission, this airglow feature has been extensively studied. McLennan and Shrum (1925) showed that the emission was from atomic oxygen, and Chapman (1931) hypothesized that it was produced by the three-body recombination of atomic oxygen to molecular oxygen. Current formulations involving a two-step process (Murtagh et al., 1990), do provide realistic values of atomic oxygen concentration.

The variability of the emission was noted by McLennan, McLeod and Ireton (1928), and by Rayleigh (1931). Later detailed studies of the seasonal and diurnal variation were made by Barbier (1959) and by Christophe-Glaume (1965). Petitdidier and Teitelbaum (1977) were able to explain the diumal variation on the basis of atmospheric tides and Teitelbaum et al. (1981) reported the observation of gravity waves and planetary waves in meteor winds and $557.7 \mathrm{~nm}$ airglow emission.

Satellite measurements have the advantage of achieving global measurements with a single instrument. The OGO 4 satellite employed nadir viewing to obtain global maps of the $557.7 \mathrm{~nm}$ emission, which showed large scale patchiness

\footnotetext{
${ }^{1}$ York University, Toronto, Carlada

${ }^{2}$ Service d'Aeronomie du CNRS, France

${ }^{3}$ Goddard Space Flight Center, Greenbelt MD

${ }^{4}$ University of Calgary, Calgary, Canada

${ }^{5}$ CRPE/CNET, Issy les Moulineaux, France

${ }^{6}$ Trent University, Peterborough, Canada

${ }^{7}$ National Research Council, Ottawa, Canada

${ }^{8}$ CEPHAG, Saint-Martin-d'Heres, France

${ }^{9}$ University of Saskatchewan, Saskatoon, Canada

${ }^{10}$ University of Western Ontario, London, Canada

${ }^{11}$ Laboratoire de Météorologie Dynamique, Palaiseau, France
}

Copyright 1993 by the American Geophysical Union.

Paper number 93GL01105

0094-8534/93/93GL-01105\$03.00
(Reed and Chandra, 1975). High latitude data were later interpreted in terms of the influence of a stratospheric warming (Walker and Reed, 1976). The OGO 6 satellite made limb scanning measurements, providing estimates of atomic oxygen density and eddy diffusion (Donahue et al., 1974). The ISIS-2 satellite yielded limb scanning data (Cogger et al., 1981), from which a mid-latitude equinoctial maximum of $557.7 \mathrm{~nm}$ emission was found. The Visible Airglow Experiment on the Atmospheric Explorer Satellites (Hays et al., 1973) provided further information on the processes that control the OI $557.7 \mathrm{~nm}$ emission.

The WINDII instrument on the Upper Atmosphere Research Satellite is the first capable of making extended aeronomical measurements of this emission on a truly global basis. This is because the orbit is circular, and data-taking is conducted 24 hours per day. In addition, the satellite has better attitude stability and knowledge than previous aeronomical satellites, providing altitude accuracy of better than $1 \mathrm{~km}$.

The first WINDII measurements of the OI $557.7 \mathrm{~nm}$ emission confirm the temporal and latitudinal variability found in earlier studies, although there is much more localized structure than expected. What is new in the WINDII data is longitudinal structure having the appearance of planetary scale waves, of wavenumbers one and two, adding a new dimension to the problem of understanding atomic oxygen variations, the related airglow emissions, and the upper atmosphere dynamics that gives rise to these variations.

\section{Brief Instrument Description}

WINDII is basically a CCD imager that views the earth's limb through a Michelson interferometer set to an optical path difference of $4.49 \mathrm{~cm}$ at $557.7 \mathrm{~nm}$. The Michelson is stepped to eight optical path difference values, each separated in phase by $45^{\circ}$, and an image is recorded at each step. WINDI has two fields of view, and acquires two images side by side on the $C C D$ detector; one views at $45^{\circ}$ to the velocity vector and the other at $135^{\circ}$. Since the UARS has an orbital inclination of $57^{\circ}$, this means that as the satellite passes its most northerly latitude of $57^{\circ} \mathrm{N}$ the fields of view sweep along a track at $42^{\circ} \mathrm{N}$, and the latitude coverage is from $72^{\circ} \mathrm{S}$ to $42^{\circ} \mathrm{N}$. How-

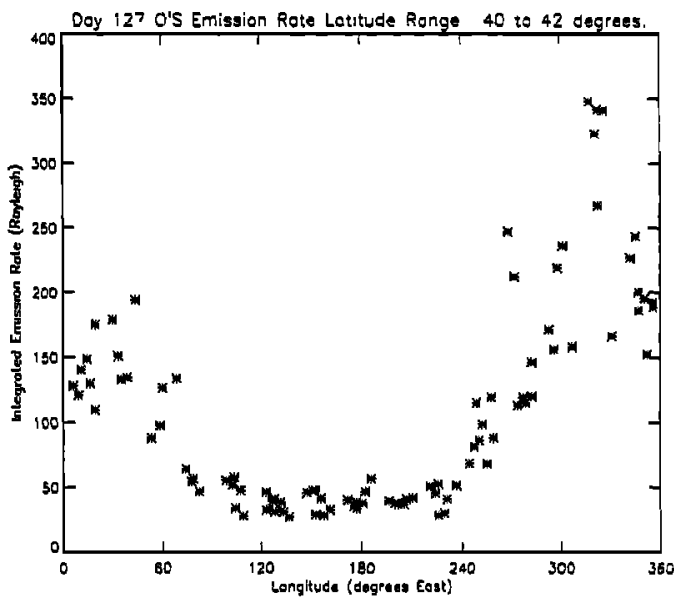

Fig. 1. Zenithal integrated emission rate for the atomic oxygen $557.7 \mathrm{~nm}$ emission as observed by WINDII on Jan. 16, 1992, plotted for the latitude band $40-42^{\circ} \mathrm{N}$. 
ever, the satellite is rotated so as to fly "backwards" on alternate months, and in this configuration the coverage is from $42^{\circ} \mathrm{S}$ to $72^{\circ} \mathrm{N}$. The bottom of the image varies around $70 \mathrm{~km}$ tangent height and the top around $300 \mathrm{~km}$. For each bin in the image, the apparent emission rate, temperature and wind are derived from the sampled sinusoidal signal; the emission rate coming from the signal mean value, the temperature from the modulation depth of the signal and the wind from the phase. These quantities are then inverted to give true altitude profiles. For the atomic oxygen $557.7 \mathrm{~nm}$ emission the exposure time is normally $2 \mathrm{~s}$ at night, and for the hydroxyl emission it is $4 \mathrm{~s}$. Other emissions are observed, but only these are reported upon in this paper. A more detailed description of the WINDII instrument is given by Shepherd et al. (1993).

\section{Data Presentation}

The inverted height profiles for the nighttime data for a 24-hour period were integrated along vertical paths over the altitude range 80 to $115 \mathrm{~km}$ in order to obtain the apparent $E$ region emission rate that would be seen by an observer on the ground. In Figure 1 we show these zenithal emission rates plotted versus longitude for the latitude range $40-42^{\circ} \mathrm{N}$ for Jan. 16, 1992. As explained above, for "forward" flight the fields of view have a most northerly latitude of $42^{\circ}$; there is thus a dense set of points in this narrow latitude band. Moreover, for one day all of these points correspond to essentially the same local time, as the orbit precesses by only about 20 min per day. We see a very strong wave-like pattern, with apparent zonal wave number 1 , peaking at $320^{\circ}$ longitude. The emission rate varies from about $30 \mathrm{R}$ at the minimum to $300 \mathrm{R}$ at the maximum.

To evaluate the long term stability of this pattem, we show in Figures 2 and 3 the zenithal emission rate plots for the same $40-42^{\circ} \mathrm{N}$ band for successive three day intervals, Jan. 19 and Jan. 22, 1992. There are missing data for some orbits due to calibrations, but there is a well-defined maximum at $240^{\circ}$ on Jan. 19 (Figure 2), and on Jan. 22 there is a clear wavenumber 2 signature, with peaks at $180^{\circ}$ and at $360^{\circ}$ (Figure 3). It is tempting to conclude that the peak at $320^{\circ}$ in Figure 1 has moved to $240^{\circ}$ in Figure 2 and in Figure 3, a movement of about $25^{\circ}$ per day, but with this limited dataset that is little more than speculation.

The same data can also be displayed as contours of volume emission rate versus altitude and longitude, as shown in Figure 4 for Jan. 22. We see here that the airglow layer is far from uniform, with the bottomside, as arbitrarily defined by 50 photon $\mathrm{cm}^{-3} \mathrm{~s}^{-1}$, varying by more than $5 \mathrm{~km}$. There is also a

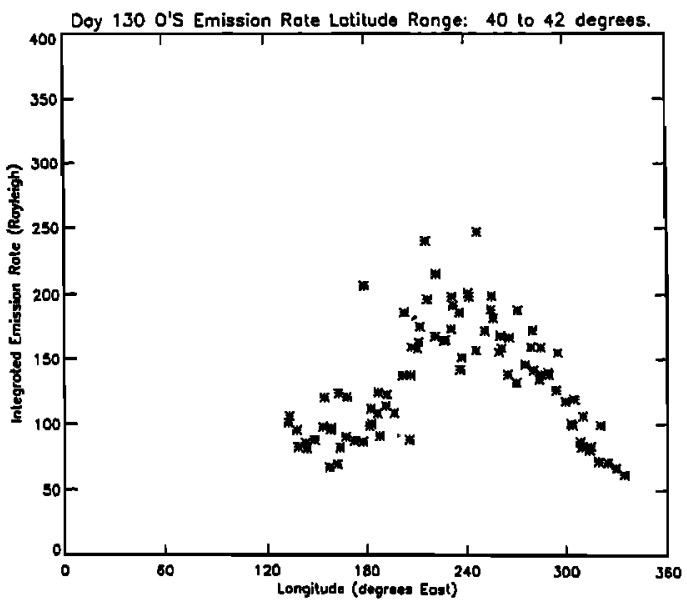

Fig. 2. Zenithal integrated emission rate for the atomic oxygen $557.7 \mathrm{~nm}$ emission as observed by WINDII on Jan. 19, 1992, plotted for the latitude band $40-42^{\circ} \mathrm{N}$.

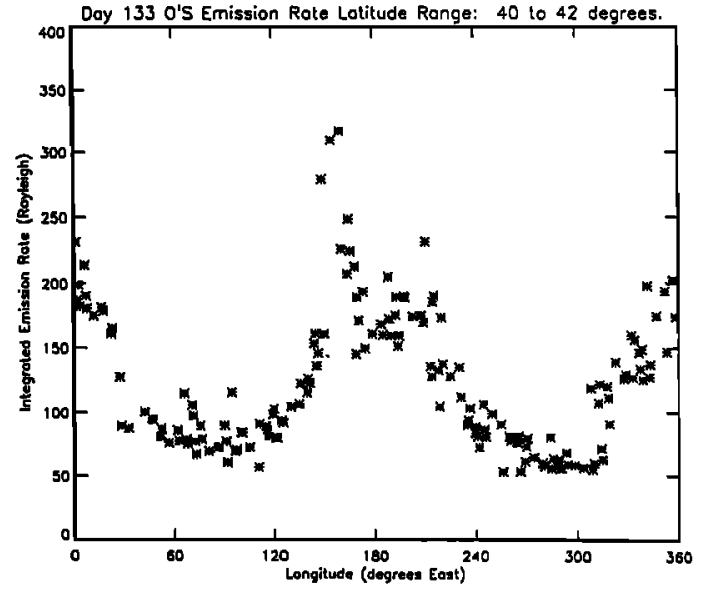

Fig. 3. Zenithal integrated emission rate for the atomic oxygen $557.7 \mathrm{~nm}$ emission as observed by WINDII on Jan. 22, 1992 , plotted for the latitude band $40-42^{\circ} \mathrm{N}$.

tendency for the regions of larger emission rate to be at lower altitude.

In Figure 5 the integrated zenithal emission rates for the latitude band $40-42^{\circ}$ for Jan. 30 are presented. The longitudinal pattern is at first sight more complex than on Jan. 19 (Figure 2) owing to the presence of some shorter wavelength structure, but there is a maximum at $180^{\circ}$ which is similar in magnitude and shape to the the $180^{\circ}$ maximum in Figure 2 . It is less prominent in Figure 5 because the maxima at $0^{\circ}$ and $360^{\circ}$ that also exist in Figure 2 are of larger amplitude in Figure 5 .

In Figure 6 we show the peak apparent emission rate for the hydroxyl Meinel emission in the $(8,3)$ band, plotted versus longitude for a latitude range $39-43^{\circ} \mathrm{N}$ for Jan. 12,1992 . Here we see a planetary wave structure with apparent zonal wavenumber 1 . The longitudinal maximum is centered near $150^{\circ}$, far from the $320^{\circ}$ maximum of Figure 1, for data taken four days later.

These emission rate variations indicate the presence of strong dynamical effects, to which the winds measured by WINDII will hopefully help provide an understanding. The wind measurements for WINDII are not finally validated, but as an example of the results obtained from the $557.7 \mathrm{~nm}$ emission at night we show in Figure 7 the meridional wind component at $97 \mathrm{~km}$, plotted versus longitude for Jan. 22 expressed as the difference from the mean. Here we see a wave-like

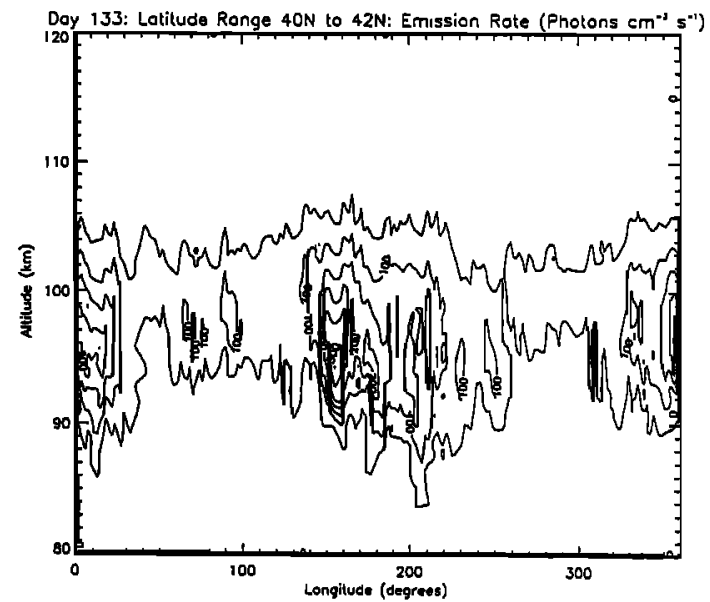

Fig. 4. Contours of volume emission rate for the atomic oxygen $557.7 \mathrm{~nm}$ emission as observed by WINDII on Jan. 22, 1992, plotted for the latitude band $40-42^{\circ} \mathrm{N}$. 


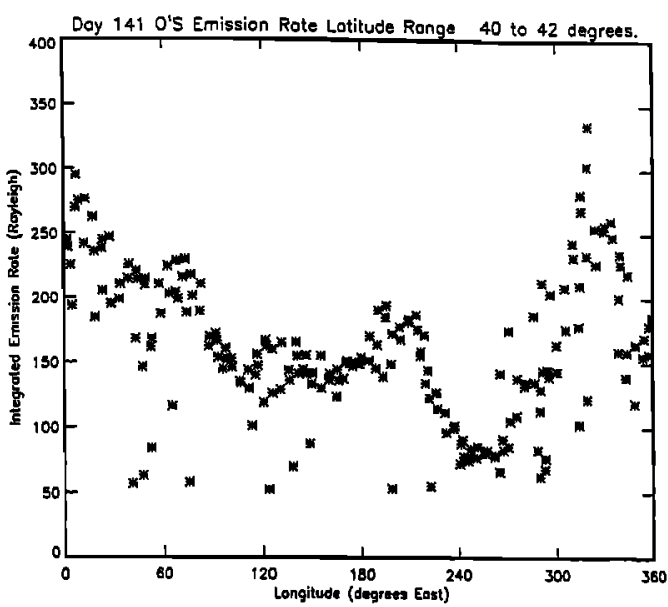

Fig. 5. Zenithal integrated emission rate for the atomic oxygen $557.7 \mathrm{~nm}$ emission as observed by WDNDII on Jan. 30 , 1992, plotted for the latitude band $40-42^{\circ} \mathrm{N}$.

structure with two maxima, of about $100 \mathrm{~ms}^{-1}$ in amplitude. One maximum is located at the $180^{\circ}$ emission rate maximumfor Jan. 22 and the other is located at the adjacent emission rate minimum.

\section{Discussion}

The results for the OI $557.7 \mathrm{~nm}$ emission and the hydroxyl emission during the month of January, 1992 show the presence, at mid-latitudes $\left(40-42^{\circ}\right)$, of planetary wave structure that appears to be a superposition of waves with apparent zonal wave numbers 1 and 2 . We say apparent, because while WINDII views the whole longitude range each day, it views each longitude at a different universal time during that day. It is therefore possible that WINDI is sampling different points on a wave that is travelling with respect to the earth. However, we believe that these waves move relatively linle from day to day, for two reasons. First, the emission rate at $0^{\circ}$ on a given day tends to be the same as at $360^{\circ}$, as shown in Figures 1,3 and 5, suggesting some measure of stability. Secondly, if such travelling waves routinely pass over ground stations during the course of a single night then all mid-latitude stations would regularly report airglow variations of a factor of four or more every night. Variations of the OI $557.7 \mathrm{~nm}$ emission observed at ground stations during the course of a single night are normally very much smaller, typically $30 \%$; these are normally attributed to gravity waves, of much shorter wavelengths and smaller periods (for examples see Wiens et al. (1992) or Teitelbaum et al. (1981)). Variations of a factor of 4 , or more, are infrequently seen at ground stations on a given night, that is, on a time scale of weeks rather than days. If the movement of $25^{\circ}$ per day suggested above were typical, though we doubt that it is, it would take two weeks for a ground station to pass through a complete cycle. Our tentative hypothesis is thus that these waves have relative stability on a time scale of days, but from time to time, suffer a dramatic change in position or planetary wave pattem distribution that causes the large scale variations observed at ground stations. This supposition is based more on existing ground-based observations, which are extensive, than on the WINDII dataset provided here, which is insufficient to allow any firm conclusions. When a more extensive WINDII dataset is employed in conjunction with selected ground stations it will be possible to resolve temporal ambiguities and thus arrive at an accurate global description of the behavior of these planetary-scale waves.

The WINDII data raise the important question as to whether these airglow emission rate variations, and the associ-

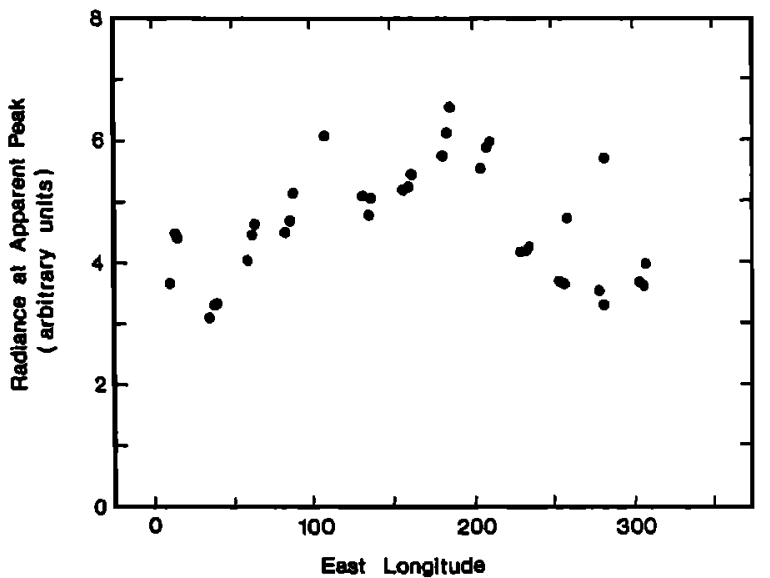

Fig. 6. Peak apparent emission rates observed at the limb for the $(8,3)$ Meinel hydroxyl band on Jan. 12, 1992, plotted for the latitude band $39-43^{\circ} \mathrm{N}$.

ated atomic oxygen concentrations, are driven by processes associated with the earth (or the lower atmosphere), rather than by the sun. Historically, aeronomers have tended to interpret airglow variations in the framework of solar-driven photochemistry. On the basis of the evidence presented here for enormous airglow variations in longitude for data all at the same local time, we conclude that the earth, or the lower atmosphere, is the origin of these variations.

One piece of supporting evidence for this is in the middle atmosphere planetary waves incorporated in the CIRA 86 model (Barnett and Labitzke, 1990). For January, at $42^{\circ} \mathrm{N}$, the geopotential altitude from this model is a combination of wavenumbers 1 and 2 . We plotted this for the maximum altitude available, $83.3 \mathrm{~km}$, and found the pattern to look similar to the waves shown in Figures 3 and 5 . The $0.5 \mathrm{~km}$ amplitude is very much smaller than the variations seen in Figure 4, and presumably smaller than required to cause such large emission rate variations. But these planetary waves do not necessarily propagate upwards from below; an alternative possibility is that upward propagating gravity waves interact with the mean flow at airglow altitudes, creating these waves there.

We now briefly mention the mechanism for airglow emission rate variation. Up until now, such variations have in general been interpreted in terms of changes in atomic oxygen concentration at a fixed altitude. The WINDII data show that airglow layers are not idealized layers at a fixed altitude, but

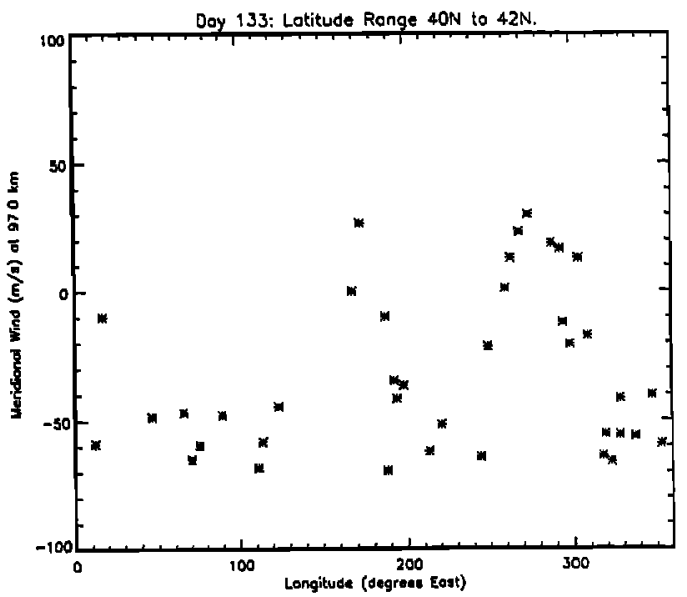

Fig. 7. The meridional wind observed by WINDII on Jan. 22, 1992 at an altitude of $97 \mathrm{~km}$ for the latitude band $40-42^{\circ} \mathrm{N}$. 
involve a good deal of horizontal and vertical structure. Airglow $557.7 \mathrm{~nm}$ enhancements may be caused by increasing the oxygen mixing ratio at a given pressure level or by increasing the total density in a given location. The latter mechanism explains the influence of gravity waves on airglow (Hines and Tarasick, 1987), with the $30 \%$ variations mentioned earlier, but the factor of four variations observed in these planetary waves would seem to require significant changes in mixing ratio.

\section{Conclusions}

We have observed planetary-scale waves in the atomic oxygen $557.7 \mathrm{~nm}$ airglow emission observed at night, in the associated meridional wind pattern. These waves are remarkable for their simple structure, dominantly consisting of wavenumbers 1 and 2, but more so for the very large peak to valley ratio, a factor of four or more. The observations are reported for a single latitude band $40-42^{\circ}$, during January, 1992 and so tell us only about winter mid-latitudes. Similar waves are observed for the hydroxyl emission. There are significant variations in the associated altitude distributions of the emissions, with a tendency for the more intense emission to be at lower altitude.

We hypothesize that the waves move relatively little on a time scale of a few days, but this response is based on the examination of a small amount of data, and a conclusive answer must await the study of the larger body of data that does exist.

The significance of these observations is that they demonstrate a strong coupling between the mesopause and the atmospheric regions below, including perhaps the earth's surface. In any case, the very existence of this planetary wave structure requires a major change in perspective regarding our present aeronomical knowledge of the mesosphere and lower thermosphere. With the development of the WINDII database we hope to contribute to the resolution of these fundâmental questions.

Acknowledgments. The WINDII project is sponsored by the Canadian Space Agency and the Centre National d'Etudes Spatiales. Additional support for science analysis is provided by the Centre National de la Recherche Scientifique and the Natural Sciences and Engineering Research Council of Canada. The authors (the WINDII co-investigators) acknowledge the suppport provided by the Upper Atmosphere Research Satellite team, and express their gratitude to NASA for their foundational support which made this project possible.

\section{References}

Barbier, D., Sur les variations systérnatiques des intensités des principales radiations de la lumiere du ciel nocturne a l'observatoire de Haute Provence, Ann Géophys., 15 , 412, 1959.

Bamett, J.J. and K. Labitzke, Climatological distribution of planetary waves in the middle atmosphere, Adv. Space Res., 10, No. 12, 12 - 63, 1990.

Chapman, S., Some phenomena of the upper atmosphere (Bakerian Lecture), Proc. Roy. Soc. (London, A 132, 353, 1931.

Christophe-Glaume, J., Etude de la raie 5577 de l'oxygene dans la luminescence atmosphérique nocturne. Ann. Géophys., 21, 1, 1965.

Cogger, L.L., R.D. Elphinstone and J.S. Murphree, Temporal and latitudinal 5577 airglow variations, Can. J. Phys., 59, 1296, 1981.

Donahue, T.M., B. Guenther and R.J. Thomas, Spatial and temporal behavior of atomic oxygen determined by Ogo 6 airglow observations, L.Geophys. Res., 72, 1959, 1974.

Hays, P.B., G. Carignan, B.C. Kennedy, G.G. Shepherd and
J.C.G. Walker, The Visible Airglow Experiment on Atmospheric Explorer, Radio Science, 8, 369, 1970.

Hines, C.O. and D.W. Tarasick, On the detection and utilization of gravity waves in airglow studies, Planet. Space Sci., 35, 851, 1987.

McLennan, J.C. and G.M. Shrum, On the origin of the auroral green line 5577 and other spectra associated with the aurora borealis, Proc. Roy, Soc. (London), A 108, 501, 1925.

McLennan, J.C., J.H. McLeod and H.J.C. Ireton, On the intensities of the light of the oxygen green line of the night sky, Transact. Roy. Soc. Canada, Sec. III, 22, 397, 1928.

Murtagh, D.P., G. Witt, J. Stegman, I.C. McDade, E.J. Llewellyn, F. Harris and R.G.H. Greer, An assessment of proposed $O\left({ }^{1} S\right)$ and $\mathrm{O}_{2}\left(b^{1} \Sigma_{z}^{*}\right)$ nightglow excitation parameters, Planet. Space Sci., 38, 43, 1990.

Petitdidier M. and $\mathbf{H}$. Teitelbaum, Lower thermosphere emissions and tides, Planet. Space Sci. 25; 711, 1977.

Rayleigh, Lord (Strutt, R.J.), Absolute intensity of the aurora line in the night sky and the number of atomic transitions, Proc.Roy Soc. (london), A 129 458, 1930.

Rayleigh, Lord (Strutt, R.J.), On a night sky of exceptional brightness, and on the distinction between the polar aurora and night sky, Proc. Roy Soc. (London). A 131, 376, 1931.

Shepherd, G.G. et al., WINDI: The Wind Imaging Interferometer on the Upper Atmosphere Research Satellite, I. Geophys. Res, June issue, 1993.

Teitelbaum, H., M. Massebeuf, J.L. Fellous, M. Petitdidier, J. Christophe and F. Blanco, Simultaneous measurements of meteor winds and green line intensity variations: Gravity waves and planetary waves, L. Geophys. Res., 86, 7767, 1981.

Walker, J.D. and E.I. Reed, Behavior of the sodium and hydroxyl nighttime emissions during a stratospheric warming, LAtmos. Sci. 33, 118, 1976.

Wiens, R.H., S.P. Zhang, R.N. Peterson, G.G. Shepherd, C.A. Tepley, L. Kieffaber, R. Niciejewski and J.H. Hecht, Simultaneous optical observations of long-period gravity waves during AIDA '89, L.Atmos. Terr. Phys., 55, 325, 1993.

G.G. Shepherd, B.H. Solheim and W.A. Gault, Institute for Space and Terrestrial Science, Centre for Research in Earth and Space Science, York University, North York, Ontario, Canada M3J 1P3.

G. Thuillier, A. Hauchecorne and M. Hers'e, Service D'Aéronomie du CNRS, Verrières-le-Buisson, France.

S. Chandra, Code 606, Goddard Space Flight Center, Greenbelt, $20771 \mathrm{MD}$.

L.L. Cogger, Department of Physics, University of Calgary, Calgary, Alberta, Canada, T2N 1N4

M.-L. Duboin, CRPE/CNET/CNRS, 92131 Issy-les-Moulineau, France.

W.F.J. Evans, Faculty of Environmental Studies, Trent University, Peterborough, Ontario, Canada K9J 7B8.

R.L. Gattinger, National Research Council, Ottawa, Ontario, Canada, K1A 0R6.

C. Lathuillere, CEPHAG, B.P. 46, 38402 Saint-Martind'Hères, France.

E.J. Llewellyn, Institute for Space and Atmospheric Studies, University of Saskatchewan, Saskatoon, Saskatchewan, Canada S7N OWO.

R.P. Lowe, Department of Physics, University of Western Ontario, London, Ontario, Canada N6A 3K7

F. Vial and $\mathrm{H}$. Teitelbaum, Laboratoire de Météorologie Dynamique, École Polytechnique, 91128 Palaiseau, France.

(Received: February 2, 1993; accepted: April 7, 1993.) 